\title{
An investigation of factors identified at birth in relation to anxiety and depression in old age: the Hordaland Health Study (HUSK)
}

\author{
Jens Christoffer Skogen ${ }^{1,2^{*}}$, Robert Stewart ${ }^{3}$, Arnstein Mykletun ${ }^{1,2}$, Marit Knapstad ${ }^{1,2}$ and Simon Øverland ${ }^{1,2}$
}

\begin{abstract}
Background: Although life course influences have long been recognised in affective disorder, little is known about the influence of early life factors on late life anxiety and depression. The aim was to investigate the extent to which birth measures, maternal health and family circumstances were associated with symptoms of anxiety and depression in late life.

Methods: A retrospective cohort study was constructed from a cross-sectional survey sample of community residents aged 72-74 years, 406 of whom had traceable birth records. Cases and controls for late life anxiety and depression were defined applying standard cut-offs to the Hospital Anxiety and Depression Scale. A range of measures and circumstances were extracted from birth records blind to survey data and compared in age- and gender-adjusted models.

Results: There were no differences in any anthropometric measure in either case control comparison. Case-level anxiety and depression were both associated with significantly lower maternal age. Late-life anxiety was additionally associated with smaller maternal pelvic size and the mother's condition being rated as poor at birth/discharge. Late-life depression was associated with a lower status paternal occupation.

Conclusions: There was no evidence for a substantial influence of early life size on late life affective disorder. However, there was some evidence in secondary analyses for an enduring influence of the family's socioeconomic environment and maternal health.
\end{abstract}

Keywords: Foetal origins of disease, Anxiety, Depression, Old age, Early life factors, Birth weight

\section{Background}

Anxiety and depression are highly prevalent disorders among older adults $[1,2]$ and, with increasing life expectancy, an area of growing clinical and public health significance [3]. A recent review of risk factors for anxiety and depression in old age highlighted personality traits, inadequate coping strategies, previous psychopathology, qualitative aspects of social networks, stressful life events and female gender as important risk factors [2]. Despite considerable overlap in risk profiles for anxiety and depression, some risk factors appear more relevant for

\footnotetext{
* Correspondence: jensskogen@gmail.com

'Department of Health Promotion and Development, Faculty of Psychology, University of Bergen, Bergen, Norway

${ }^{2}$ Division of Mental Health, Department of Public Mental Health, Norwegian Institute of Public Health, Bergen, Norway

Full list of author information is available at the end of the article
}

depression specifically, including chronic diseases, poor self-perceived health, functional disability, shrinking social networks and being unmarried [2]. Facing this combination of proximal and distal risk factors, a life-course perspective including risk factors originating from the early-life environment [4], is potentially indicated.

The developmental origins of adult health and disease (DOHAD), originally known as "the Barker hypothesis", is commonly applied as the framework for understanding empirically observed links between processes at prenatal stages and adult chronic disease [5,6]. The DOHAD-hypothesis suggests that prenatal risk factors, from intrauterine environmental exposures, affect the foetus irreversibly during specific developmental periods. Thus, according to the hypothesis, the risk of specific diseases such as coronary heart disease and non-insulin 
dependent diabetes in adult life, will be elevated across the life-span for those who are exposed to the relevant risks in foetal life [7]. A key practical challenge in research on the hypothesis is to attain information about the offspring's development during pregnancy. Anthropometric measures such as birth weight, birth length and head circumference are routinely, and often reliably recorded, and therefore often used as proxy measures [8].

The DOHAD-hypothesis has also been applied to investigate the aetiology of mental disorders, proposing that prenatal factors can modify risk [9]. Low birth weight has been linked to increased risk of suicide $[10,11]$, schizophrenia [12], and autism [13], as well as with anxiety and depression [4,9,14-27]. In 2007, Alati and colleagues [9] reported an inverse linear association between birth weight and depressive symptoms at age 21 in females, but not in males. Wiles and colleagues found the same pattern in relation to risk for psychological distress among middle-aged individuals of both genders [20].

To our knowledge, only three studies have investigated the impact of early life factors and late-life mental health. Thompson and colleagues found that foetal undernutrition predisposed men, but not women, to depression at age 68 [14]. A recent Swedish study found that women born at a lower gestational age and those born with a birth weight less than the median, were more likely to have reported lifetime depression with a follow-up of 92 years of age [25]. As the latter study investigated the risk of life-time depression, however, the finding may not reflect an enduring risk of gestational age and birth weight for depression into old age. On the other hand, Gale and colleagues found no association between birth weight and anxiety and depression at age 64-79 as reported on the Hospital Anxiety and Depression Scale [28] in five different cohorts [4]. Other studies in younger populations have also failed to identify associations between foetal or very early life factors and mental disorders in adolescence, early adulthood and mid-life [29-34], leaving the question open for debate [27]. A recent systematic review investigating the foetal origins of depression included 18 studies and compared those of low birth weight $(<2500 \mathrm{~g})$ to those of normal birth weight $(>2500 \mathrm{~g})$ [35]. The authors found evidence for a weak association (random effects estimate of OR 1.15 (CI95\% 1.00-1.32)) between low birth weight and later depression or psychological distress, but also indications of publication bias. Furthermore, studies of associations between perinatal status and later mental disorders have been criticized for relying too much on birth weight as the indicator of the foetal environment [4] and this may contribute to the heterogeneous results, in addition to different lengths of follow-up. It has also been argued that associations may be more prominent in females and less identifiable in male-only cohorts [36].

In summary, there is some evidence suggesting an association between foetal and early origins of anxiety and depression in adulthood. This is however not consistently supported in the literature, with study design differences and elements of publication bias suggested as possible reasons for heterogeneity. Compared to research on depression in old age, anxiety disorders have received very little attention [37], despite similar prevalences to depression in old age [38] and high levels of co-morbidity with depression $[2,38]$.

Taking advantage of a birth record archive in an area covered by a cross-sectional survey of older people's mental health in Bergen (Norway), we constructed retrospective cohort study to investigate the relationship between the early life environment and late life anxiety and depression. This allowed for a follow-up from the 1920s to the 1990s. Primary hypotheses were that smaller anthropometric measures would be associated with case status for both syndromes. Secondary analyses investigated other information reflecting parental health and early life socioeconomic status.

\section{Cohort context - characteristics of Bergen in the early 20th century and life expectancy}

During the late 19th century and early 20th century, Bergen city expanded geographically and qualitatively from a semi-rural city to one with more modern characteristics. Primary industry which had dominated, gave ground to expanding secondary and tertiary industry [39]. This change in industry was mostly due to growing production and manufacturing, but also due to an increase in commerce, shipping, transport and service sectors [39]. As a consequence of this, three social classes began to dominate in Bergen during the same period, upper (bourgeoisie), middle and lower, with large differences in income, housing standard and diet. The upper class was characterised by industry proprietors, importers, wholesale dealers and financers. The middle class consisted primarily of merchants, craftsmen and officials, while the lower class comprised regular workers or artisans [39]. During 1925 and 1927 the life expectancy at birth in Norway was approximately 67 years for males, and 74 years for females [40].

\section{Methods}

\section{Study population}

The sampling frame for this study comprised all 3,341 (77\% of the invited) participants of the old age cohort of the population-based Hordaland Health Study (HUSK) which has been previously described [41]. In summary, all residents of Bergen city or neighbouring areas born 
between 1925 and 1927 of a previously established study population were invited to participate in a general physical examination and to complete questionnaires on socio-demographic status, general health and healthrelated behaviour. HUSK was conducted from 1997 to 1999 as a collaboration between the National Health Screening Service, the University of Bergen and local health services.

In this study, we sought to link as many members as possible of the HUSK sample to their birth records in order to construct a nested retrospective cohort study within the linked subgroup, comparing historically recorded information at birth between participants with/ without a mental disorder in late life. In the Norwegian Population Registry, all inhabitants of Norway are registered with a personal identification number. Using this individual identifier, the names (and maiden name for females), date of birth, place of birth and parents' names (if available) of HUSK participants were retrieved. This information was used to trace the participants born in Bergen to the public maternity ward ("Fødestiftelsen i Bergen") birth records located at the Regional State Archives of Bergen. In the second decade of the 20th century, about one quarter of all births in the Bergen area took place in the official maternity ward (personal communication, State archivist). The portion of deliveries taking place at hospitals increased steeply when the new Women's Clinic ("Kvinneklinikken") was inaugurated in 1926, replacing the old maternity ward. The relevant birth records for the present study were those detailing births between 1st of January 1925 and 31st of December 1927. These records contain detailed information about the pregnancy, the birth and the mother's health recorded by midwives and obstetricians during the hospital stay. The Women's Clinic in question was the main teaching facility for midwifes at the time, and the records were integral to the training, and are therefore considered to be of high quality [42].

Early life factors - information obtained at birth, 1925-27 The available birth records in the Regional State Archives of Bergen were viewed and coded by researchers blind to all measurements made in HUSK. The following information was abstracted from each record (directly copying original information unless stated otherwise): birth weight $(\mathrm{kg})$, birth length $(\mathrm{cm})$, head circumference $(\mathrm{cm})$ at birth, ponderal index (PI; calculated from weight divided by the third power of length), mother's pelvic size $(\mathrm{cm})$, mother's age (years), and gestation (weeks). The following binary variables were derived from individual free text fields: any recorded disease in the mother, family history of coronary heart disease (yes/no) and tuberculosis (yes/no), the state of mother's teeth (poor/good), complications during birth (yes/no), mother's condition after birth (poor/good; based on the midwives description of the mother (e.g. fatigued, pale, swollen and feverish)), mother's condition at discharge (poor/good; based on the midwives description of the mother (e.g. pale, swollen and feverish), and indicators of socioeconomic status included marital status (married/unmarried), father's occupation (unskilled/manual vs skilled manual/ non-manual), and type of payment for the hospital stay (health insurance/not insurance).

\section{Anxiety and depression - follow-up in HUSK at age 72-74} Cases and controls were defined according to the presence of anxiety and depressive symptoms in late life, ascertained in HUSK participants using the Hospital Anxiety and Depression Scale (HADS) [28]. HADS assesses anxiety (HADS-A) and depression (HADS-D) on two separate subscales, each consisting of seven questions. The HADS has been used extensively in previous community-based research and is considered a reliable and valid screening tool, with little measurement variance as a function of age in the general population $[43,44]$. As HADS was developed for a hospital setting, no somatic symptoms of anxiety or depression are included, which renders it especially suitable for assessment in an old age population where significant comorbidity with physical health conditions is anticipated [45]. In accordance with previous studies, the mean score for all individuals with five or more valid responses on each subscale was computed [44]. We employed the recommended cut-offs to define caseness (both $\geq 8$ ), which have been found to yield an optimal balance between sensitivity and specificity (both 0.8 ) [43]. Applying these cut-offs, two dichotomous variables for case-level anxiety and depression were created, where the controls for anxiety could include case-level depression and vice versa. Our findings are equivalent when employing a control group restricted to only noncases or HADS as a continuous measure (data not shown).

\section{Additional demographic information - follow-up from HUSK at age 72-74}

To assess potential demographic differences between the participants we were able to trace and the remaining HUSK participants, we obtained gender, self-reported level of educational attainment and general health from HUSK. Level of educational attainment was divided into "compulsory only" and "post-compulsory", while general health was divided into "poor" and "good".

\section{Statistical analyses}

Of the 3,341 HUSK-participants [41], we were able to trace 480 to their birth records. Out of these, 406 (84.6\%) had five or more valid responses on each HADS 
subscale (comparable to the rest of the HUSKparticipants) allowing late life case/control status to be ascertained and constituted the total study population. The sample was described, HUSK participants with traceable birth records were compard to the remainder of the sample, and the traced with and without valid HADS-subscales were compared in relation to the exposures. For primary analyses, previous exposure status was compared between cases and controls using ageand gender-adjusted linear regression analyses for continuous exposures and similarly adjusted logistic regression models for categorical exposures. In order to assess adverse conditions in the womb, the association between birth weight and case-level anxiety and depression was adjusted for gestational age in addition to age and gender. In total, 18 potential exposures were investigated in relation to each HADS subscale. Although not entirely uncontroversial, considering the explorative nature of the study and the limited sample size, we chose not to adjust for multiple comparisons. For the significant associations, we also performed a secondary analyses adjusting for educational attainment and self-reported general health at participation in HUSK. Stata version 11.0 [46] was employed for all analyses presented in this paper.

Using the software G*Power version 3.1.3 [47], a post hoc power analysis indicated that we would be able to detect a small to medium effect size for mean group differences (Cohen's $d$ of 0.39) and binary associations (Cohen's $w$ of 0.18 ), given a power of $80 \%$ for the main HADS-A and HADS-D analyses [48-51].

\section{Ethics}

The data in HUSK was collected in accordance with ethical standards required by the regional ethical board of Committees for Medical and Health Research Ethics in Norway (REC). The permission to collect and store the data from HUSK was given by the Norwegian Data Inspectorate. All participation in HUSK was voluntary, and all potential participants received written information about the project before they met for examination. The participants gave their written statements of informed consent, including the specific consents to use information from HUSK in health research and to link this information with other relevant data sources. The participants also gave their written statement that they were informed that no specific time-limit was set for the storage of data. This specific study was reviewed and approved by REC. The current study adheres to the standards of the declaration of Helsinki.

\section{Results}

No differences between the HUSK-participants with birth journal information and participants without were found regarding gender $(\mathrm{p}=0.814)$, self-reported health $(\mathrm{p}=0.706)$, case-level anxiety $(\mathrm{p}=0.531)$ or case-level depression $(\mathrm{p}=0.621)$. However, participants we were able to trace had a significantly higher educational attainment $(p=0.025)$ than the untraced. The proportion of participants with case-level anxiety and case-level depression in the traced sample was $14.3 \%$ and $9.4 \%$, respectively. No differences were found on exposures obtained at birth between those with valid HADS subscales $(n=406)$ and those without $(\mathrm{n}=74)$, all $\mathrm{p}$-values ranging between 0.087-0.990. Out of the 406 HUSK-participants included in the present study, $54.2 \%$ (CI95\% 49.3-59.0) were female, and the mean age was 72.3 (SD: 0.9) years. The sample-characteristics obtained at birth are summarized in Table 1.

In the main analyses, none of the anthropometric measures at birth, such as weight and length, differed significantly between cases and controls in either comparison (Table 2), and out of the 36 bivariate associations investigated, only 6 (16.7\% CI95\% 3.9\%-29.5\%) were statistically significant (Tables 2 and 3). For continuous and ordinal exposures, both case-level anxiety and depression were associated with lower mother's age $(\mathrm{p}=0.027$ and $\mathrm{p}=0.036$, respectively), and case-level anxiety was associated with a smaller maternal pelvic size $(\mathrm{p}=0.017)$. For binary exposures, case-level anxiety was associated with an increased odds of the mother's condition after birth or at discharge being rated as poor (p-values 0.001 and 0.012 respectively). Case-level depression was associated with an increased odds of a lower occupational status for the father $(\mathrm{p}=0.029)$. There were no substantial differences between the crude model and age- and gender-adjusted model for any of the associations investigated, and modelling the HADS-subscales as continuous outcomes also yielded similar results as did restriction of controls to those with neither anxiety nor depression (data not shown). For the significant results, adjusting for educational attainment and selfreported general health in HUSK only minimally changed the estimates (data not shown).

\section{Discussion \\ Main findings}

Many previous studies have found an association between early life factors and later mental health problems, but most of these have been limited to follow-up into childhood, early adulthood or middle-age. In this study investigating risk factors present at birth in relation to anxiety and depression in old age, no associations were found for the anthropometric measures of principal interest. However, there was evidence in secondary analyses for associations with factors that might indicate worse maternal health and/or socioeconomic status. 
Table 1 Sample characteristics at birth obtained from medical records

\begin{tabular}{|c|c|c|c|c|}
\hline & $\mathrm{N}=$ & Mean & Proportion (\%) & Standard deviation \\
\hline Birth weight $(\mathrm{kg})$ & 406 & 3.47 & - & 0.51 \\
\hline Birth length $(\mathrm{cm})$ & 406 & 50.30 & - & 2.04 \\
\hline Head circumference $(\mathrm{cm})$ & 400 & 34.47 & - & 1.66 \\
\hline Ponderal Index & 406 & 2.65 & - & 0.22 \\
\hline Mother's pelvic size $(\mathrm{cm})$ & 382 & 26.05 & - & 1.30 \\
\hline Mother's age (years) & 406 & 29.24 & - & 5.73 \\
\hline Parity & 406 & 2.57 & - & 1.94 \\
\hline Gestational time (weeks) & 406 & 39.67 & - & 1.18 \\
\hline Gender (\% female) & 406 & - & $54.2 \%$ & - \\
\hline Mother's condition after birth (\% poor) & 406 & - & $9.9 \%$ & - \\
\hline Tuberculosis in family (\% yes) & 406 & - & $10.8 \%$ & - \\
\hline CVD in family (\% yes) & 406 & - & $11.6 \%$ & - \\
\hline Mother's condition at discharge (\% poor) & 406 & - & $23.2 \%$ & - \\
\hline Complications birth (\% yes) & 406 & - & $9.6 \%$ & - \\
\hline Father's occupation (\% manual/unskilled) & 406 & - & $59.4 \%$ & - \\
\hline Unmarried (\% yes) & 406 & - & $3.9 \%$ & - \\
\hline Teeth lower jaw (\% poor) & 394 & - & $57.9 \%$ & - \\
\hline Payment (\% not insurance) & 289 & - & $57.1 \%$ & - \\
\hline Number of diseases $(\%>1)$ & 406 & - & $30.0 \%$ & - \\
\hline
\end{tabular}

\section{Strengths and limitations}

This study had several strengths. Having access to birth records from the 1920s and the possibility to link this information to a population-based health survey in the late 1990s enabled examination of an interval between exposure/outcome status in the range of 72-74 years. The exposure source contained detailed, accurate and rich anthropometric measurements (such as birth weight in kilograms with two decimal places), as well as information about maternal health and circumstances, the birth process and the early post-natal period. This information is unlikely to be biased in any particular direction. The birth records were carried out as a key element in the education of midwives under the supervision of the head physician. The HUSK study included a validated and often used screening inventory for symptoms of anxiety and depression. Furthermore, both men and women were represented in our sample, enabling identification of any confounding by gender.

Limitations include the relatively small sample size and proportion of the HUSK-participants that could be traced back to their birth records. There are several reasons for this: the birth records were only available for a subgroup as not everyone who participated in HUSK was born in the Bergen area, and some born at home or at other hospitals. Based on a conservative estimate, at least one-third of the HUSK sample would not be within the catchment area of the regional hospital at the time of birth. The small sample size reduces our ability to detect potential small but meaningful effects. A recent meta-analysis investigating the association between low birth weight and depression later on found only small effects [35] - and given the lack of precision in our estimates such small effects may not be detectable in our study. In previous DOHAD-studies which have used birth cohorts to trace individuals in their adulthood (i.e. forward tracing), the identified proportions of the original sample are sometimes as low as $2-5 \%$ [52]. The low traceability and small sample size constitute central limitations to our study, and warrants caution with regards to the interpretation and generalisability of the present study. For birtweight in particular, the small sample size precluded any investigation of low birth weight $(<2.5 \mathrm{~kg})$ or high birthweight $(>4.5 \mathrm{~kg})$ per se, which is associated with later psychopathology in some studies [53,54]. Due to long follow-up between the exposures and the outcomes, survival and selection effects are likely to influence the nature of the sample overall, including a healthy survivor effect [55], and nonparticipation bias [56] rendering the participants in our sample healthier than those from other studies in younger age groups. It is, however, unlikely that such effects would substantially influence the exposure-outcome associations of interest since both cases and controls were survivors and drawn from the same source population. Also we did not find any systematic differences in gender, self- 
Table 2 Associations between late life anxiety and depression case status and continuous or ordinal exposures recorded at birth

\begin{tabular}{|c|c|c|c|c|c|c|}
\hline & \multicolumn{2}{|l|}{ Mean (SD) } & \multirow{2}{*}{$\begin{array}{l}\text { Age- and } \\
\text { gender- } \\
\text { adjusted } \\
\text { mean } \\
\text { difference } \\
(95 \% \mathrm{Cl})\end{array}$} & \multicolumn{2}{|l|}{ Mean (SD) } & \multirow{2}{*}{$\begin{array}{l}\text { Age- and } \\
\text { gender- } \\
\text { adjusted } \\
\text { mean } \\
\text { difference } \\
(95 \% \mathrm{Cl})\end{array}$} \\
\hline & Case-level anxiety & Controls & & $\begin{array}{l}\text { Case-level } \\
\text { depression }\end{array}$ & Controls & \\
\hline \multirow[t]{2}{*}{ Birth weight $(\mathrm{kg})^{\mathrm{a}}$} & 3.38 & 3.48 & -0.06 & 3.42 & 3.48 & -0.05 \\
\hline & $(0.48)$ & $(0.51)$ & $(-0.18,0.06)$ & $(0.62)$ & $(0.50)$ & $(-0.20,0.09)$ \\
\hline \multirow[t]{2}{*}{ Birth length $(\mathrm{cm})$} & 49.92 & 50.36 & -0.21 & 50.00 & 50.33 & -0.41 \\
\hline & $(2.15)$ & $(2.02)$ & $(-0.78,0.35)$ & $(2.49)$ & $(1.99)$ & $(-1.08,0.25)$ \\
\hline \multirow[t]{2}{*}{ Head circumference $^{\mathrm{b}}(\mathrm{cm})$} & 34.28 & 34.50 & -0.07 & 34.34 & 34.48 & -0.23 \\
\hline & $(1.52)$ & $(1.68)$ & $(-0.54,0.39)$ & $(1.93)$ & $(1.63)$ & $(-0.78,0.32)$ \\
\hline \multirow[t]{2}{*}{ Ponderal Index } & 2.64 & 2.65 & -0.01 & 2.64 & 2.65 & -0.00 \\
\hline & $(0.23)$ & $(0.22)$ & $(-0.07,0.05)$ & $(0.27)$ & $(0.22)$ & $(-0.08,0.07)$ \\
\hline \multirow[t]{2}{*}{ Mother's pelvic size ${ }^{c}(\mathrm{~cm})$} & 25.65 & 26.11 & $-0.44^{*}$ & 25.89 & 26.06 & -0.22 \\
\hline & $(1.28)$ & $(1.29)$ & $(-0.82,-0.06)$ & $(1.05)$ & $(1.32)$ & $(-0.67,0.23)$ \\
\hline \multirow[t]{2}{*}{ Mother's age (years) } & 27.69 & 29.50 & $-1.97^{*}$ & 27.37 & 29.43 & $-2.14^{*}$ \\
\hline & $(5.85)$ & $(5.67)$ & $(-3.59,-0.35)$ & $(5.77)$ & $(5.70)$ & $(-4.07,-0.22)$ \\
\hline \multirow[t]{2}{*}{ Parity } & 2.26 & 2.63 & -0.40 & 2.24 & 2.61 & -0.39 \\
\hline & $(1.38)$ & $(2.02)$ & $(-0.95,0.15)$ & $(1.72)$ & (1.96) & $(-1.05,0.26)$ \\
\hline \multirow[t]{2}{*}{ Gestation (weeks) } & 39.63 & 39.67 & 0.00 & 39.62 & 39.67 & -0.05 \\
\hline & $(1.14)$ & $(1.18)$ & $(-0.33,0.34)$ & $(1.14)$ & $(1.18)$ & $(-0.45,0.34)$ \\
\hline$N$ & 58 & 348 & 406 & 38 & 368 & 406 \\
\hline
\end{tabular}

${ }^{*} p<0.05,{ }^{* *} p<0.01,{ }^{* * *} p<0.001$.

${ }^{\mathrm{a} B i r t h}$ weight was also adjusted for gestational age.

${ }^{\mathrm{b}} \mathrm{N}=400$ (Males $\mathrm{N}=183$ and females $\mathrm{N}=217$ ).

${ }^{\mathrm{c}} \mathrm{N}=382$ (Males $\mathrm{N}=174$ and females $\mathrm{N}=208$ ).

reported health or HADS-scores between the participants we were able to trace, and the remainder of the HUSKparticipants, suggesting reasonable generalisability beyond the analysed sample.

The outcome measure, HADS, is a screening instrument for anxiety and depression, primarily designed to measure these syndromes in a general hospital population. In the age group in this study, a measurement which specifically focuses on cognitive rather than somatic symptoms of anxiety and depression may have benefits in avoiding over-ascertainment due to physical health problems, which are relatively common in this age group. The HADS has been found to have good case-finding properties in a GP setting [57] although remains a screening tool rather than a diagnostic instrument. Furthermore, the cutoff $\geq 8$ have been shown to provide the optimal balance between sensitivity and specificity in previous studies, but it is not clear whether this cutoff is optimal in older age groups. Some studies have suggested a cutoff $\geq 11$ in older populations [45], but we chose to use 8 due to limitations in sample size. In relation to the number of associations investigated (36 in total), we decided not to adjust for multiple comparison, which is in line with some recommendations [58]. Applying Bonferroni adjustments would reduce the number of significant associations to one (case-level anxiety associated with mother's condition after birth) but not change our conclusions dramatically. Other limitations were that information on maternal health and family circumstances as from the birth records was relatively crude, and gestational time had relatively litthe variance (with only $8.9 \%$ delivered before 40 weeks). These may have obscured some associations, although systematic bias is unlikely since the information gathering in HUSK was unlikely to have been influenced by birth circumstances and the information from the birth records was historic and transcribed blind to case status.

\section{Interpretation of our findings}

Out of the three previously published papers on the relationship between factors present at birth and anxiety and depression in old age $[4,14,25]$, only one has included both genders [4]. The authors of the latter also employed HADS as the outcome measure, and found no 
Table 3 Associations between case-level anxiety and depression, and dichotomous exposures in the birth journals

\begin{tabular}{|c|c|c|c|c|c|c|}
\hline & $\begin{array}{l}\text { Case-level } \\
\text { anxiety (\%) }\end{array}$ & $\begin{array}{l}\text { Controls } \\
\text { (\%) }\end{array}$ & $\begin{array}{l}\text { Age- and gender-adjusted } \\
\text { OR }(95 \% \mathrm{Cl})\end{array}$ & $\begin{array}{l}\text { Case-level } \\
\text { depression (\%) }\end{array}$ & $\begin{array}{l}\text { Controls } \\
\text { (\%) }\end{array}$ & $\begin{array}{l}\text { Age- and gender-adjusted } \\
\text { OR }(95 \% \mathrm{Cl})\end{array}$ \\
\hline \multirow{2}{*}{$\begin{array}{l}\text { Mother's condition after } \\
\text { birth ( } \% \text { poor) }\end{array}$} & 22.4 & 7.8 & $5.29^{* * *}$ & 7.9 & 10.1 & 1.00 \\
\hline & & & $(2.30-12.19)$ & & & $(0.28-3.54)$ \\
\hline \multirow{2}{*}{$\begin{array}{l}\text { Tuberculosis in family (\% } \\
\text { yes) }\end{array}$} & 8.6 & 11.2 & 0.69 & 5.3 & 11.4 & 0.42 \\
\hline & & & $(0.25-1.85)$ & & & $(0.10-1.81)$ \\
\hline \multirow[t]{2}{*}{ CVD in family (\% yes) } & 10.3 & 11.8 & 0.93 & 2.6 & 12.5 & 0.18 \\
\hline & & & $(0.37-2.34)$ & & & $(0.02-1.34)$ \\
\hline \multirow{2}{*}{$\begin{array}{l}\text { Mother's condition at } \\
\text { discharge (\% poor) }\end{array}$} & 36.2 & $21.0 \%$ & $2.05^{*}$ & 34.2 & 22.0 & 1.75 \\
\hline & & & $(1.11-3.77)$ & & & $(0.85-3.60)$ \\
\hline \multirow[t]{2}{*}{ Complications birth (\% yes) } & 10.3 & 9.5 & 1.04 & 18.4 & 8.7 & 2.35 \\
\hline & & & $(0.41-2.64)$ & & & $(0.95-5.82)$ \\
\hline \multirow{2}{*}{$\begin{array}{l}\text { Father's occupation (\% } \\
\text { unskilled/manual) }\end{array}$} & 55.2 & 60.1 & 0.75 & 76.3 & 57.6 & $2.36^{*}$ \\
\hline & & & $(0.42-1.32)$ & & & $(1.08-5.15)$ \\
\hline \multirow[t]{2}{*}{ Unmarried (\% yes) } & 8.6 & 3.2 & 2.50 & 7.9 & 3.5 & 2.23 \\
\hline & & & $(0.81-7.75)$ & & & $(0.59-8.42)$ \\
\hline \multirow[t]{2}{*}{ Teeth lower jaw ${ }^{a}(\%$ poor) } & 57.1 & 58.0 & 0.89 & 52.6 & 58.4 & 0.83 \\
\hline & & & $(0.49-1.60)$ & & & $(0.42-1.64)$ \\
\hline \multirow{2}{*}{$\begin{array}{l}\text { Payment }{ }^{b} \text { ( } \% \text { not } \\
\text { insurance) }\end{array}$} & 59.1 & 56.7 & 1.08 & 62.5 & 56.4 & 1.21 \\
\hline & & & $(0.54-2.16)$ & & & $(0.55-2.66)$ \\
\hline \multirow[t]{2}{*}{ Number of diseases $(>1)$} & 25.9 & 30.8 & 0.76 & 31.6 & 29.9 & 1.11 \\
\hline & & & $(0.40-1.47)$ & & & $(0.53-2.31)$ \\
\hline$N$ & 58 & 348 & 406 & 38 & 368 & 406 \\
\hline
\end{tabular}

association between birth weight and anxiety or depression in old age across five different cohorts. They did not investigate other factors present at birth, and speculated that birth weight might be a too crude marker for fetal neurodevelopment [4]. We expanded on this potential limitation, and included several anthropometric measures, as well as factors like mother's condition, maternal familial history of disease and socioeconomic status. Interpretation of our secondary analysis should be done with caution, but the present results are indicative of possible continuation of socioeconomic disadvantage and an adverse impact for the offspring if the health in the mother was judged as poor during the hospital stay. Younger maternal age might lead to less experienced upbringing, or might reflect differences in socioeconomic position. The lack of association with parity at birth, however, does not suggest that the inverse association between case-level anxiety and depression with maternal age is because of participants' positions in their sibships.
Associations with smaller pelvic size might be explained by poor nutrition during the mother's childhood, which in turn could negatively affect the development of the placenta and fetus in late pregnancy [59], although it might also increase the risk of a difficult labour. Worse condition of the mother is of interest as this could reflect a variety of issues, including post-natal disorder, somatic illness or lower socioeconomic position. There was also some suggestion in our findings that socioeconomic markers were more associated with depression, and physical health markers more with anxiety.

Our results are, however, not in line with the finding from the Swedish study where both low birth weight and shorter gestational age at birth were independent risk factors for life-time depression among women [25], although this may be related to the previously mentioned low variance in gestational age in our sample. There are other reasons as to why few of the indicators were associated with anxiety and depression in old age. 
First, it is possible that factors identified at birth are more important in early or mid-life, but become less relevant as the time between exposure and outcome increases. Instead, other more proximal factors become stronger predictors of anxiety and depression in old age, such as social environment [60] stressful life-events and loss of function $[2,4]$. Second, is possible that other measures of the foetal environment than those used here would be better indicators of any true link to anxiety and depression in old age, such as the size and shape of the placental surface [61].

\section{Conclusions}

As the life expectancy in many societies has increased, many individuals will live longer, and the pool of older adults with mental disorders will increase. Despite this development, less attention has been directed towards identifying risk factors for late life mental disorders, especially anxiety, than in younger age groups [38,62]. A better understanding of risk factors across the life-span, also during early life and foetal development, is needed, as this might help to increase identification and treatment of mental disorders in old age [2]. Our findings indicate that there is only a weak association between status at birth and anxiety and depression in old age, and it might be that the effects of these risk factors are restricted to early or mid-life mental disorders. Although there was no clear evidence of any impact from educational attainment and physical health later in life for the investigated associations, a better perspective might be to adopt a life-course perspective or developmental origins of health and disease perspective, where foetal and early life-factors are considered in conjunction with physical and social exposures across the whole life-span [63-65]. This will allow for the exploration of early life factors' potential impact on and ability to modify later exposures related to the development of symptoms of anxiety and depression.

\section{Competing interests}

The authors declare that they have no competing interests.

\section{Authors' contributions}

JCS, AM and RS were responsible for the conception this study, and the study design was developed by JCS, AM and RS. Analyses were carried out by JCS under supervision of RS and $S \varnothing$, and manuscript preparation was led

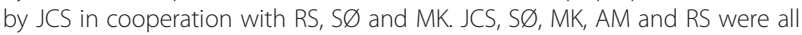
involved in the interpretation of data, drafting the article and approval of the final manuscript. JCS is the guarantor for the study.

\section{Acknowledgements}

This manuscript is part of the first author's PhD-thesis that was funded by the Research Council of Norway. Beyond that, no specific funding was received for this research.

\section{Author details}

${ }^{1}$ Department of Health Promotion and Development, Faculty of Psychology, University of Bergen, Bergen, Norway. ${ }^{2}$ Division of Mental Health, Department of Public Mental Health, Norwegian Institute of Public Health, Bergen, Norway. ${ }^{3}$ King's College London (Institute of Psychiatry), London, UK.
Received: 7 November 2012 Accepted: 6 May 2013

Published: 10 May 2013

\section{References}

1. Gonçalves DC, Pachana NA, Byrne GJ: Prevalence and correlates of generalized anxiety disorder among older adults in the australian national survey of mental health and well-being. J Affect Disord 2011, 132(1-2):223-230.

2. Vink D, Aartsen MJ, Schoevers RA: Risk factors for anxiety and depression in the elderly: a review. J Affect Disord 2008, 106:29-44.

3. Gallo JJ, Lebowitz BD: The epidemiology of common late-life mental disorders in the community: themes for the new century. Psychiatr Serv 1999, 50(9):1158-1166.

4. Gale CR, Sayer AA, Cooper C, Dennison EM, Starr JM, Whalley LJ, Gallacher JE, Ben-Shlomo Y, Kuh D, Hardy R, et al: Factors associated with symptoms of anxiety and depression in five cohorts of community-based older people: the HALCyon (healthy ageing across the life course) programme. Psychol Med 2011, 41(10):2057-2073.

5. Barker DJP: Fetal and infant origins of adult disease. Monatsschr Kinderheilkd 2001, 149(Suppl 1):s2-s6.

6. Skogen JC, Øverland S: The fetal origins of adult disease: a narrative review of the epidemiological literature. JRSM Short Reports 2012, 3:

7. Barker DJP: The developmental origins of adult disease. J Am Coll Nutr 2004, 23(suppl 6):588S-595S.

8. Wilcox AJ: On the importance - and the unimportance - of birthweight. Int J Epidemiol 2001, 30:1233-1241.

9. Alati R, Lawlor DA, Mamun AA, Williams GM, Najman JM, O'Callaghan M, Bor $W$ : Is there a fetal origin of depression? evidence from the mater university study of pregancy and its outcome. Am J Epidemiol 2007, 165:575-582.

10. Barker DJP, Osmond C, Rodin I, Fall CHD, Winter PD: Low weight gain in infancy and suicide in adult life. BMJ 1995, 311:1203.

11. Mittendorfer-Rutz E, Wasserman D, Rasmussen F: Fetal and childhood growth and the risk of violent and non-violent suicide attempts: a cohort study of 318953 men. J Epidemiol Community Health 2008, 62(2):168-173

12. Cannon M, Jones PB, Murray RM: Obsteric complications and schizophrenia: historical and meta-analytic review. Am J Psychiatry 2002, 159:1080-1092.

13. Kolevzon A, Gross R, Reichenberg A: Prenatal and perinatal risk factors for autism: a review and integration of findings. Arch Pediatr Adolesc Med 2007, 161:326-333.

14. Thompson C, Syddall H, Rodin I, Osmond C, Barker DJP: Birth weight and the risk of depressive disorder in late life. Br J Psychiatry 2001, 179(5):450-455.

15. Nilsson PM, Nyberg P, Östergren P-O: Increased susceptibility to stress at a psychological assessment of stress tolerance is associated with impaired fetal growth. Int J Epidemiol 2001, 30(1):75-80.

16. Cheung YB: Early origins and adult correlates of psychosomatic distress. Soc Sci Med 2002, 55(6):937-948.

17. Cheung YB, Khoo KS, Karlberg J, Machin D: Association between psychological symptoms in adults and growth in early life: longitudinal follow up study. BMJ 2002, 325(7367):749-751.

18. Gale CR, Martyn CN: Birth weight and later risk of depression in a national birth cohort. Br J Psychiatry 2004, 184(1):28-33.

19. Costello EJ, Worthman C, Erkanli A, Angold A: Prediction from low birth weight to female adolescent depression: a test of competing hypotheses. Arch Gen Psychiatry 2007, 64(3):338-344.

20. Wiles NJ, Peters TJ, Leon DA, Lewis G: Birth weight and psychological distress at age 45-51 years. BMJ 2005, 187(1):21-28.

21. Raikkonen $K$, Pesonen A-K, Heinonen $K$, Kajantie $E$, Hovi $P$, Jarvenpaa $A-L$, Eriksson JG, Andersson S: Depression in young adults with very low birth weight: the helsinki study of very Low-birth-weight adults. Arch Gen Psychiatry 2008, 65(3):290-296.

22. Paile-Hyvärinen M, Räikkönen K, Forsén T, Kajantie E, Ylihärsilä H, Salonen MK, Osmond C, Eriksson JG: Depression and its association with diabetes, cardiovascular disease, and birth weight. Ann Med 2007, 39(8):634-640.

23. Nomura Y, Wickramaratne PJ, Pilowsky DJ, Newcorn JH, Bruder-Costello B, Davey C, Fifer WP, Brooks-Gunn J, Weissman MM: Low birth weight and risk of affective disorders and selected medical illness in offspring at high and low risk for depression. Compr Psychiatry 2007, 48(5):470-478. 
24. Van Lieshout RJ, Boylan K: Increased depressive symptoms in female but not male adolescents born at low birth weight in the offspring of a national cohort. Can J Psychiatry 2010, 55(7):422-430.

25. Gudmundsson P, Andersson S, Gustafson D, Waern M, Östling S, Hällström T, Palsson S, Skoog I, Hulthen L: Depression in swedish women: relationship to factors at birth. Eur J Epidemiol 2011, 26(1):55-60.

26. Betts KS, Williams GM, Najman JM, Alati R: The association between birth weight and anxiety disorders in young adults. J Anxiety Disord 2011, 25(8):1060-1067

27. Inskip HM, Dunn N, Godfrey KM, Cooper C, Kendrick T: Is birth weight associated with risk of depressive symptoms in young women? evidence from the southampton Women's survey. Am J Epidemio/ 2008, 167(2):164-168.

28. Zigmond A, Snaith R: The hospital anxiety and depression scale. Acta Pscyhiatrica Scandinavica 1983, 67:361-370

29. Osler $M$, Nordentoft $M$, Andersen A-MN: Birth dimensions and risk of depression in adulthood: cohort study of danish men born in 1953. $\mathrm{Br} J$ Psychiatry 2005, 186(5):400-403.

30. Lagerström M, Bremme K, Eneroth P, Janson C-G: Long-term development for girls and boys at age 16-18 as related to birth weight and gestational age. Int J Psychophysiol 1994, 17(2):175-180.

31. Sabet F, Richter LM, Ramchandani PG, Stein A, Quigley MA, Norris SA: Low birthweight and subsequent emotional and behavioural outcomes in 12year-old children in soweto, south africa: findings from birth to twenty. Int J Epidemiol 2009, 38(4):944-954.

32. Vasiliadis HM, Gilman SE, Buka SL: Fetal growth restriction and the development of major depression. Acta Psychiatr Scand 2008, 117(4):306-312.

33. Fan AP, Eaton WW: Longitudinal study assessing the joint effects of socio-economic status and birth risks on adult emotional and nervous conditions. Br J Psychiatry 2001, 178(40):s78-s83.

34. Cooke RWl: Health, lifestyle, and quality of life for young adults born very preterm. Arch Dis Child 2004, 89(3):201-206

35. Wojcik W, Lee W, Colman I, Hardy R, Hotopf M: Foetal origins of depression? A systematic review and meta-analysis of low birth weight and later depression. Psychological Medicine 2013, 43:1-12.

36. Rice $F$, Jones $T$, Thapar $A$ : The impact of gestational stress and prenatal growth on emotional problems in offspring: a review. Acta Psychiatr Scand 2007, 115:171-183.

37. Wetherell $J$, Maser JD, Balkom AV: Anxiety disorders in the elderly: outdated beliefs and a research agenda. Acta Psychiatr Scand 2005, 111(6):401-402.

38. Beekman AT, de Beurs E, van Balkom AJLM, Deeg DJ, van Dyck R, van Tilburg W: Anxiety and depression in later life: Co-occurence and communality of risk factors. Am J Psychiatry 2000, 157:89-95.

39. Ertresvaag E: Bergen bys historie III, Et bysamfunn i utvikling 1800-1920 [the history bergen city (volume 3). a urban society in development 1800-1920]. Bergen: Universitetsforlaget; 1982

40. Mamelund S-E, Borgan J-K: Kohort- og periodedødelighet i Norge 18461994 [Cohort and Period Mortality in Norway 1846-1994]. In Rapport: Endringer. Edited by Statistics Norway. Oslo: Statistics Norway; 1996.

41. Refsum H, Nurk E, Smith AD, Ueland PM, Gjesdal CG, Bjelland I, Tverdal A, Tell GS, Nygård O, Vollset SE: The hordaland homocysteine study: a community-based study of homocysteine, its determinants, and associations with disease. J Nutr 2006, 136(6):1731S-1740S.

42. Rosenberg M: Inntrykk fra arbeid med de gamle fødejournalene [impression after working with the historical birth records]. In Jordmorutdanning og kvinneklinikk : tilbakeblikk og status etter 125 år i bergen : jubileumsskrift for bergen jordmorhøgskole og kvinneklinikken. Edited by Haram K, Bergsjø P. Bergen: Kvinneklinikken, Haukeland Sykehus; 1987.

43. Bjelland I, Dahl A, Haug T, Neckelmann D: The validity of the hospital anxiety and depression scale. An updated literature review. Journal of Psychosomatic Research 2002, 52:69-77.

44. Mykletun A, Stordal E, Dahl A: Hospital anxiety and depression (HAD) scale: factor structure, item analyses and internal consistency in a large population. Br J Psychiatry 2001, 179:540-544.

45. Flint A, Rifat S: Factor structure of the hospital anxiety and depression scale in older patients with major depression. Int J Geriatr Psychiatry 2002, 17:117-123.

46. StataCorp: Statistical software: release 11.0. College Station, TX: Stata Corporation; 2010

47. Faul F, Erdfelder E, Lang A-G, Buchner A: GPOWER: a general power analysis program. Behav Res Meth Instrum Comput 2007, 28:1-11.
48. Cohen J: Statistical power analysis for the behavioral sciences (2nd ed.) Lawrence Earlbaum Associates: Hillsdale, NJ; 1988.

49. Van Voorhis CRW, Morgan BL: Understanding power and rules of thumb for determining sample sizes. Tutorials in Quantitative Methods for Psychology 2007, 3(2):43-50.

50. Mayr S, Erdfelder E, Buchner A, Faul F: A short tutorial of GPower. Tutorials in Quantitative Methods for Psychology 2007, 3(2):51-59.

51. Cohen J: A power primer. Psychol Bull 1992, 112(1):155-159.

52. Joseph KS, Kramer MS: Review of the evidence on fetal and early childhood antecedents of adult chronic disease. Epidemiol Rev 1996, 18(2):158-174

53. Colman I, Ploubidis GB, Wadsworth MEJ, Jones PB, Croudace TJ: A longitudinal typology of symptoms of depression and anxiety over the life course. Biol Psychiatry 2007, 62(11):1265-1271.

54. Vasiliadis H-M, Buka SL, Martin LT, Gilman SE: Fetal growth and the lifetime risk of generalized anxiety disorder. Depress Anxiety 2010, 27(11):1066-1072.

55. Baillargeon J, Wilkinson GS: Characteristics of the healthy survivor effect among male and female hanford workers. Am J Ind Med 1999, 35:343-347.

56. Knudsen AK, Hotopf M, Skogen JC, Øverland S, Mykletun A: The health status of nonparticipants in a population-based health study: the hordaland health study. Am J Epidemiol 2010, 172(11):1306-1314.

57. Olsson I, Mykletun A, Dahl A: The hospital anxiety and depression rating scale: a cross-sectional study of psychometrics and case finding abilities in general practice. BMC Psychiatry 2005, 5:46-46.

58. Rothman KJ: No adjustments Are needed for multiple comparisons Epidemiology 1990, 1(1):43-46.

59. Martyn CN, Barker DJP, Osmond C: Mothers' Pelvic size, fetal growth, and death from stroke and coronary heart disease in men in the UK. Lancet 1996, 348(9037):1264-1268.

60. Kelly YJ, Nazroo JY, McMunn A, Boreham R, Marmot M: Birthweight and behavioural problems in children: a modifiable effect? Int J Epidemiol 2001, 30:88-94.

61. Barker DJP, Thornburg KL, Osmond C, Kajantie E, Eriksson JG: Beyond birthweight: the maternal and placental origins of chronic disease. Journal of Developmental Origins of Health and Disease 2010, 1(6):360-364.

62. Beekman ATF, Geerlings SW, Deeg DJH, Smit JH, Schoevers RS, de Beurs E, Braam AW, Penninx BWJH, Van Tilburg W: The natural history of late-life depression - a 6-year prospective study in the community. Arch Gen Psychiatry 2002, 59(7):605-611.

63. Ben-Shlomo Y: Rising to the challenges and opportunities of life course epidemiology. Int J Epidemiol 2007, 36:481-483.

64. Bateson P, Barker D, Clutton-Brock T, Deb D, D'Udine B, Foley RA, Gluckman P, Godfrey K, Kirkwood T, Lahr MM, et al: Developmental plasticity and human health. Nature 2004, 430:419-421.

65. Gluckman PD, Hanson MA, Buklijas T: A conceptual framework for the developmental origins of health and disease. Journal of Developmental Origins of Health and Disease 2010, 1(01):6-18.

\section{doi:10.1186/1471-244X-13-136}

Cite this article as: Skogen et al: An investigation of factors identified at birth in relation to anxiety and depression in old age: the Hordaland Health Study (HUSK). BMC Psychiatry 2013 13:136.

\section{Submit your next manuscript to BioMed Central and take full advantage of:}

- Convenient online submission

- Thorough peer review

- No space constraints or color figure charges

- Immediate publication on acceptance

- Inclusion in PubMed, CAS, Scopus and Google Scholar

- Research which is freely available for redistribution 